Pak. j. sci. ind. res. Ser. A: phys. sci. 2017 60(3) 172-174

\title{
Short Communication \\ Heavy Metal Content of Refined and Bakery Salts Consumed in Pakistan
}

\author{
Abrar ul Hassan ${ }^{a *}$, Sakhawat Ali ${ }^{\mathrm{b}}$, Salman Muhsen ${ }^{\mathrm{a}}$ and Muhammad Rizwan ${ }^{\mathrm{c}}$ \\ a'Department of Chemistry, University of Management and Technology, Joher Town, Lahore, Pakistan \\ ${ }^{b}$ Food and Biotechnology Research Centre (FBRC), PCSIR Laboratories Complex, Lahore -54600, Pakistan \\ ${ }^{\mathrm{c}}$ Department of Chemistry, Minhaj University, Lahore, Pakistan
}

(received November 12, 2016; revised February 21, 2017; accepted March 3, 2017)

\begin{abstract}
This study involved the investigation of heavy metal contents of 100 refined and an equal number of bakery refined table salt samples collected from the local markets of Lahore, Faisalabad and Gujranwala, Pakistan. Levels of lead, copper, cadmium and iron were estimated using an atomic absorption spectrophotometer. The results indicated a mean $\pm \mathrm{SD}$ in $\mu \mathrm{g} / \mathrm{g}$ levels in the refined table salt samples for lead (0.85 \pm 0.22$)$, copper $(1.37 \pm 0.25)$, cadmium $(0.41 \pm 32)$ and iron (7.72 \pm 2.1$)$. For bakery refined table salts values for same metals ranged $1.61 \pm 0.51,2.07 \pm 1.2,0.71 \pm 0.21$ and $12.6 \pm 5.1$, respectively. Obtained results were compared with the maximum limits recommendations for human consumption set by Codex Alimentarius Commission.
\end{abstract}

Keywords: heavy metals, refined salts, bakery salts

Table salt is widely employed food additive in the world and its role is central to the lives of public, therefore exposure of heavy metals even in trace amounts may lead to serious consequences. Contamination of environment samples like food, salt and water is increasing day by day in various countries (Cheraghali et al., 2010).

Heavy metals may be ingested through food and drink (Heshmati et al., 2014). Table salt is important biologically because of provision of two important macro elements sodium and chloride to living systems (Lindgren, 1922). Beside the $\mathrm{Na}^{+}$and $\mathrm{Cl}^{-}$ions in the common salt, some other inorganic trace minerals such as calcium, magnesium, iron and sculpture are also present (Khaniki et al., 2007). Proportion of these minerals is higher in unrefined salts. In addition it is also important as food additive and as a preservative to enhance the shelf life (Jacob and Morvood, 1971). During the mining process there is evidences of removal of many essential trace minerals (André, 1990). Recently, incidence of heavy metal contamination in table salt has been investigated worldwide (Soylak et al., 2008). Minerals are incorporated into the food chain due to their persistent nature and in this way can lead to serious problems for human health (Alam et al., 1975). Contaminations of table salt even in trace amounts may lead to

*Author for correspondence;

E-mail: hassanabrar428@yahoo.com serious consequences. Table salt in various countries like Brazil, Turkey, Iran, Poland, Nigeria and Greece etc., has been found to be contaminated with heavy metals (Soylak et al., 2008; Sharif et al., 2007). Unrefined table salt from Pakistan has been evaluated recently by Hassan et al. (2016). During the present research refined and bakery table salt samples were collected from local markets of three populous cities of Pakistan in order to know the status of heavy metal contents of lead, copper, cadmium and iron.

Collection of samples. Hundred of refined and bakery refined table salt samples were collected from the local markets of Lahore, Gujranwala and Faisalabad, Pakistan. All the collected samples had clear specifications of their purity level and other mineral content such as magnesium, calcium and moisture etc. In the laboratory the samples were transferred into air tight glass containers.

Reagents and solutions. All reagents used during the present study were of analytical grade from BDH. 1000 $\mathrm{mg} / \mathrm{L}$ stock solutions of metals to be determined were diluted to prepare the standard solutions in $1 \mathrm{~mol} \mathrm{HNO}_{3}$. No preconcentration technique was applied.

Statistical analysis. $T$-test method was used for the difference among the heavy metal levels in salt samples Codex limit $\mathrm{p}<0.05$ was considered as a significant difference. 
Heavy metal analysis. A Hitachi Z8000 (Japan) model of atomic spectrophotometer was employed for heavy metal determination. Operating conditions for studied metals are enlisted in Table 1 which are earlier reported by Abrar et al. (2016). $2.5 \mathrm{~g}$ of $24 \mathrm{~h}$ oven dried (100 ${ }^{\circ} \mathrm{C}$ ) salt sample was dissolved in $6 \mathrm{~mL}$ of $\mathrm{HNO}_{3}$ to make a slurry. This slurry was then placed for $24 \mathrm{~h}$ at room temperature for digestion of metals covered with watch glass. Solution made by diluting the slurry into doubly distilled water and making the final volume of $100 \mathrm{~mL}$ was then heated at $110^{\circ} \mathrm{C}$ for $3 \mathrm{~h}$ for digestion of metals. A blank digest was also prepared by the same method. Metals were determined in the aqueous solution.

Concentrations of all the toxic metals were recorded in $\mu \mathrm{g} / \mathrm{g}$ and are enlisted in Table 2 for refined table salt samples and in Table 3 for bakery salt samples. Mean \pm SD range of refined table and bakery salt samples are shown in Fig. 1-2, respectively. Interference of intellectual and cognitive development in children and cardiovascular and high blood pressure disorders in adults are found to be associated with the exposure of lead (Zukowska and Biziuk, 2008). Codex standard allows $2.0 \mu \mathrm{g} / \mathrm{g}$ of lead in food grade salt (CAC, 2011).

Content of lead in refined and unrefined table salts from Greece, Turkey and Egypt were in the range of 0.5 to $1.64 \mu \mathrm{g} / \mathrm{g}$ (Jacob and Morvood, 1971). For Brazil its range was 0.03 to $0.10 \mu \mathrm{g} / \mathrm{g}$ (Soylak et al., 2008) and for Iran its range was 0.01 to $5.8 \mu \mathrm{g} / \mathrm{g}$ (AL-Rajhi, 2014).

Table 1. Operating conditions for AAS

\begin{tabular}{lllll}
\hline \hline Metals & $\lambda_{(\max )}$ & Flame gases & $\begin{array}{l}\text { Flame } \\
\text { atomisation }\end{array}$ & $\begin{array}{l}\text { Maximum } \\
\text { lamp current }\end{array}$ \\
\hline $\mathrm{Cd}$ & 228.8 & Air-acetylene & 1.5 & 8 \\
$\mathrm{Cu}$ & 324.8 & Air-acetylene & 4 & 10 \\
$\mathrm{Fe}$ & 248 & Air-acetylene & 5 & 30 \\
$\mathrm{~Pb}$ & 283.3 & Air-acetylene & 20 & 15 \\
\hline \hline
\end{tabular}

Table 2. Mean \pm SD range of refined table salt samples $(\mu \mathrm{g} / \mathrm{g})$

\begin{tabular}{llll}
\hline \hline Heavy metals & Mean \pm SD & Range & $\begin{array}{l}\text { Codex Standard } \\
150 \text { limit }\end{array}$ \\
\hline Lead $(\mathrm{Pb})$ & $0.847 \pm 0.217$ & $1.24-0.41$ & 2 \\
Copper $(\mathrm{Cu})$ & $1.37 \pm 0.252$ & $2.1-0.32$ & 2 \\
Cadmium $(\mathrm{Cd})$ & $0.41 \pm 0.32$ & $0.31-0.12$ & 0.5 \\
Iron $(\mathrm{Fe})$ & $7.72 \pm 2.10$ & $8.9-2.70$ & - \\
\hline \hline
\end{tabular}

Present results showed that the concentration of cadmium in refined and bakery refined table salt samples ranged between 0.31 to $0.12 \mu \mathrm{g} / \mathrm{g}$ and 0.087 to $1.00 \mu \mathrm{g} / \mathrm{g}$ which were slightly higher than the values obtained from the refined salts in Iran, Turkey and Greece, having value 0.14 to $0.30 \mu \mathrm{g} / \mathrm{g}$ (Jacob and Morvood, 1971). Codex Alimentarius Commission permits a $0.5 \mu \mathrm{g} / \mathrm{g}$ of cadmium (Codex stan 150). Copper in the samples were detected

Table 3. Mean \pm SD range of bakery refined table salt samples $(\mu \mathrm{g} / \mathrm{g})$

\begin{tabular}{llll}
\hline \hline Heavy metals & Mean \pm SD & Range & $\begin{array}{l}\text { Codex Standard } \\
150 \text { limit }\end{array}$ \\
\hline Lead $(\mathrm{Pb})$ & $1.61 \pm 0.51$ & $0.52-1.91$ & 2 \\
Copper $(\mathrm{Cu})$ & $2.07 \pm 1.2$ & $1.61 \pm 2.51$ & 2 \\
Cadmium $(\mathrm{Cd})$ & $0.71 \pm 0.21$ & $0.087-1.00$ & 0.5 \\
Iron $(\mathrm{Fe})$ & $12.6 \pm 5.1$ & $5.6-12.1$ & - \\
\hline \hline
\end{tabular}

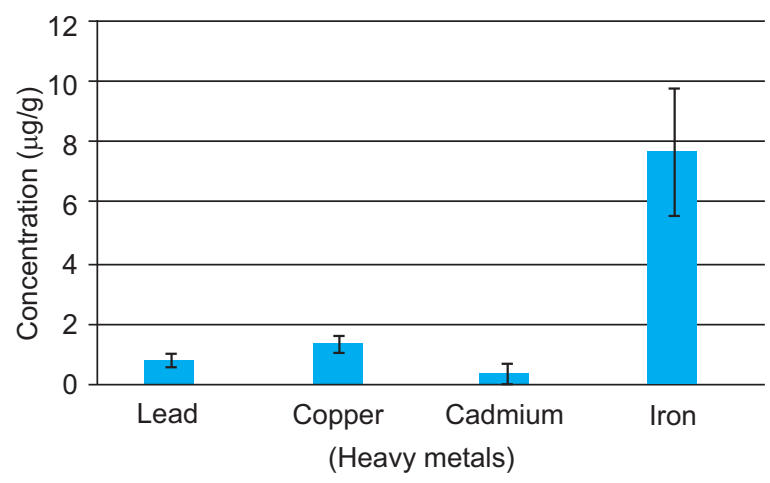

Fig. 1. Mean \pm SD range of refined table salt samples.

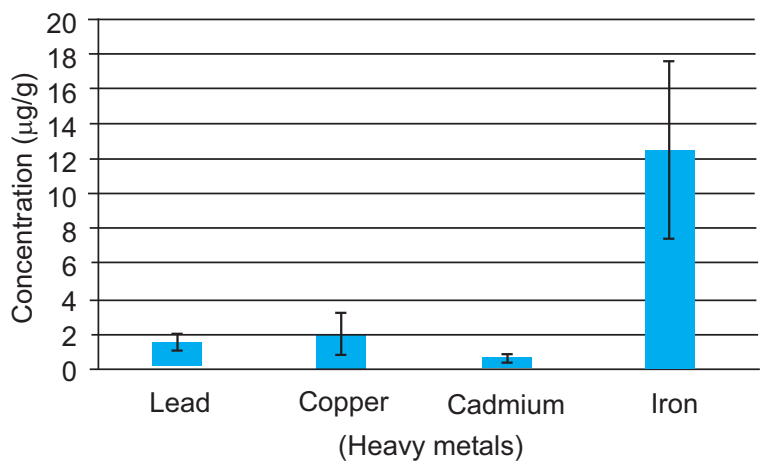

Fig. 2. Mean \pm SD range of bakery refined table salt samples. 
having the range of 2.1 to $0.32 \mu \mathrm{g} / \mathrm{g}$ for refined salt and from 1.61 to 2.51 for bakery refined salts. $2 \mu \mathrm{g} / \mathrm{g}$ of copper is permitted as a maximum human consumption by Codex. Previous literature has reported 0.17 to 0.47 $\mu \mathrm{g} / \mathrm{g}$ of copper in table salt samples (Watson, 1993).

Iron is involved in cellular metabolism, neurotransmitter synthesis and in myelin (Chen et al., 2011). So, it is important for normal functioning of brain and nervous system (Jacob and Morvood, 1974). About 50-400 $\mu \mathrm{g} /$ day of iron is recommended for daily use of iron (Sharif et al., 2007).

\section{Conclusion}

All the salt samples of refined and bakery table salt samples had a lower contents of heavy metals as compared to legal limit set by Codex Alimentarius Commission. However, higher concentration of heavy metals than the previously reported data suggests that contamination should be reduced by adopting the advanced method of purification and refining of salts.

\section{References}

AL-Rajhi, M.A. 2014. Study of some heavy metals and trace elements. Physics International, 5: 128-131.

Alam, G.S., Hussain, A., Asrarullah. 1975. The mapping of Warcha and Kalabagh salt and potash investigations, Punjab, Pakistan. Records of Geological Survey of Pakistan, 40: 14.

André, W. 1990. Al Hind. The Making of the Indo Islamic World. 171 pp. Brilliant Academic Publishers, Suffolk, UK.

Chen, C., Qian, Y., Chen, Q., Li, C. 2011. Assessment of daily intake of toxic elements due to consumption of vegetables, fruits, meat, and seafood by inhabitants of Xiamen, China. Journal of Food Sciences, 76: $181-188$.

Cheraghali, A., Kobarfard, F., Faeizy, N. 2010. Heavy metals contamination of table salt consumed in Iran. Iranian Journal of Pharmaceutical Research, 9: 129-132.

CAC, 2011. Codex Alimentatius Commission, Joint FAO/WHO Food Standards Programme, pp. 122.

Hassan, A., Ali, S., Mohyuddin, A. 2016. Chemical characterization of unrefined rock salt deposits of Pakistan. Pakistan Journal of Scientific and Industrial Research, 59: 126-129.

Heshmati, A., Vahidinia, A., Salehi, I. 2014. Evaluation of heavy metal contamination of unrefined and refined table salt samples. International Journal of Research Studies in Bioscience, 2: 21-24.

Jacob, A., Morvood, M. 1971. Blood and its disorders, 135 pp. Hardesty and Weather eds., Blackwell, Oxford, UK.

Khaniki, G.R.J., Dehghani, M.H., Mahvi, A.H., Nazmara, S. 2007. Determination of trace metal contaminants in edible salts in Tehran (Iran) by atomic absorption spectrophotometry. Journal of Biological Sciences, 7: 811-814.

Lindgren, W. 1922. A suggestion for the terminology of certain mineral deposits. Economic Geology, 17: 292-294.

Sharif, Q.M., Hussain, M., Hussain, M.T., Ahmad, V.U., Shah, M.R. 2007. Chemical evaluation of major salt deposits of Pakistan. Journal of Chemical Society of Pakistan, 29: 569-574.

Soylak, M., Peker, D.S., Turkoglu, O. 2008. Heavy metal contents of refined and unrefined table salts from Turkey, Egypt and Greece. Environment Monitoring and Assessment, 143: 267-272.

Watson, D.H. 1993. Safety of Chemicals in Food: Chemical Contaminants, 109 pp. Ellis Horwood Publishers, New York, UK.

Zukowska, J., Biziuk, M. 2008. Methodological evaluation method of dietary heavy metal intake. Journal of Food Science, 73: 1-9. 